\title{
The Critical Illness Polyneuropathy in Septic Patients With Prolonged Weaning From Mechanical Ventilation: Is the Diaphragm Also Affected? A Pilot Study
}

\author{
Patrícia dos Santos MD, Cassiano Teixeira MD PhD, Augusto Savi PT, \\ Juçara Gasparetto Maccari MD, Fernanda Santos Neres MD, \\ André Sant'Ana Machado MD, Roselaine Pinheiro de Oliveira MD MSc PhD, \\ Marlise Ribeiro MD PhD, and Francisco T Rotta MD
}

\begin{abstract}
BACKGROUND: Critical illness myopathy and/or neuropathy (CRIMYNE) is a common alteration seen in the ICU. The currently available bedside methods of measuring respiratory and peripheral muscle function in critically ill patients are somewhat inadequate. The objective of this study was to evaluate the presence of diaphragmatic and peripheral CRIMYNE in septic patients with prolonged weaning from mechanical ventilation (MV). METHODS: Cohort prospective study with an entry period of 6 months. In 2 Brazilian medical-surgical ICUs, septic patients $\geq 18$ years of age, dependent on MV $\geq 14$ days, requiring prolonged weaning from MV, awake (Richmond Agitation Sedation Scale $\geq-2$ ), and with no previous history of polyneuropathy or myopathy were included. Electrophysiological studies of the limbs and also of the respiratory system by phrenic nerve conduction and needle electromyography of the diaphragm were performed in all subjects. RESULTS: Twelve subjects were enrolled during 6 months of study. The electrophysiological signs of peripheral CRIMYNE occurred in 9 subjects, 7 of whom died in the ICU. Three subjects developed critical illness polyneuropathy, 4 critical illness myopathy, and 2 both. Only one subject who developed peripheral CRIMYNE did not present diaphragmatic involvement, whereas no subject developed diaphragm involvement alone. Thus, electrophysiological signs of diaphragmatic CRIMYNE occurred in 8 of the 9 subjects with peripheral CRIMYNE. Upon clinical examination, 8 subjects were not able to moves their limbs against gravity, and these findings were related to the presence of peripheral and diaphragmatic dysfunction. $\mathrm{CON}$ CLUSIONS: Our pilot findings suggested that CRIMYNE is common in septic patients with prolonged weaning from MV (MV $\geq 14 \mathrm{~d}$ ). The inability to move limbs against gravity is frequently associated with peripheral and diaphragmatic CRIMYNE, and the findings of CRIMYNE in peripheral electrophysiological tests are associated with diaphragmatic involvement. Key words: critical illness polyneuropathy; critical illness myopathy; weaning; mechanical ventilation; diaphragm injury. [Respir Care 2012;57(10): 1594-1601. () 2012 Daedalus Enterprises]
\end{abstract}

\section{Introduction}

Complications that can delay recovery from critical illness represent a major concern for critical care physicians,

Drs Santos and Rotta are affiliated with the Department of Neurophysiology; and Drs Maccari, Neres, Machado, and Oliveira are affiliated with the Intensive Care Unit, Santa Casa Hospital, Porto Alegre, Rio Grande do Sul, Brazil. Dr Teixeira is affiliated with the Intensive Care Unit; and Mr Savi is affiliated with the Department of Physiotherapy, Moinhos de Vento Hospital, Porto Alegre, Rio Grande do Sul, Brazil. Dr Ribeiro is affiliated with the Department of Neurology, Medical School, and neuromuscular disturbances are now well recognized as adverse events that can affect long-term ventilated pa-

Universidade Federal de Ciências da Saúde de Porto Alegre, Porto Alegre, Rio Grande do Sul, Brazil.

The authors have disclosed no conflicts of interest.

Correspondence: Cassiano Teixeira MD PhD, Intensive Care Unit, Moinhos de Vento Hospital, Ramiro Barcelos 910/605, Porto Alegre, Rio Grande do Sul 90640-010 Brazil. E-mail: cassiano.rush@gmail.com

DOI: $10.4187 /$ respcare.01396 


\section{The Critical Illness Polyneuropathy in Septic Patients With Prolonged Weaning}

tients. ${ }^{1-3}$ Although diverse disorders can afflict the muscular and peripheral nervous system in these patients, critical illness myopathy (CIM) and/or neuropathy (CRIMYNE) is the most clearly defined neuromuscular complication. ${ }^{4-7}$

Critical illness polyneuropathy (CIP), an acute sensorymotor axonal polyneuropathy, is the most common and the best defined neuromuscular alteration seen in the ICU, 8 affecting $58 \%$ of patients with prolonged ICU stay, $70 \%$ to $80 \%$ of patients with sepsis, septic shock, or multi-organ failure, and up to $100 \%$ of patients with sepsis and coma. ${ }^{9}$ CIM is a primary muscle disorder that has been observed only in recent years. ${ }^{10}$ The true incidence of CIM is unknown, because neither the diagnosis of CIM nor the differential diagnosis between CIP and CIM in the ICU are easy; furthermore, it requires specialized neurophysiological methods or biopsy investigations in addition to conventional nerve conduction studies and needle electromyography (EMG). When these methods are used, CIM is as frequent as, or more frequent than CIP. However, according to bedside methods, both conditions are collectively called CRIMYNE, and they are usually suspected in ICU patients who, after a period of days or weeks, cannot be weaned from the ventilator despite the absence of pulmonary or cardiac causes of respiratory failure, or because they suffer from various degrees of limb weakness. ${ }^{4}$

Investigators ${ }^{11-14}$ have demonstrated that multipleorgan system failure secondary to sepsis, hyperglycemia, and prolonged mechanical ventilation (MV) are strongly associated with the development of CRIMYNE. Ischemia or injury via mediators of inflammation are the most common invoked pathways to produce nerve and muscle injury, as well as evidence for low-level, local immune system activation with release of both pro-inflammatory and anti-inflammatory cytokines in the muscle of patients with CRIMYNE. Tissue injury may lead to the influx of inflammatory cells and to the release of such cytokines. The expression of adhesion molecules on vascular endothelium suggests the possible contribution of increased vascular permeability. ${ }^{12}$

The newest international consensus conference ${ }^{15}$ proposed to categorize weaning patients into 3 groups, according to the difficulty and length of the weaning process. The simple weaning group includes patients who successfully pass the first spontaneous breathing trial (SBT) and are extubated successfully. The difficult weaning group includes patients who fail in the first SBT and require up to 3 attempts or 7 days for achieving successful weaning. The last group is the prolonged weaning group, who need more than 7 days or more than 3 SBTs for weaning success. Some researchers ${ }^{15-17}$ estimate that $15 \%$ of patients would be in the prolonged weaning group, while previous studies disagree on whether ${ }^{18-21}$ or not ${ }^{22,23}$ CRYMINE prolongs the duration of MV.

\section{QUICK LOOK}

\section{Current knowledge}

Critical illness polyneuropathy is the most common and best defined acquired neuromuscular disorder during ICU stay, and is most common following sepsis and the associated therapies. Critical illness myopathy is a primary muscle disorder affecting these patients, but its incidence is not well described.

\section{What this paper contributes to our knowledge}

Critical illness myopathy and/or neuropathy is common in septic patients requiring prolonged mechanical ventilation ( $\geq 14$ days). Patient inability to move limbs against gravity is frequently associated with peripheral and diaphragmatic weakness.

Critically ill patients are exposed to a combination of insults that affect both respiratory and peripheral skeletal muscle function. ${ }^{24}$ However, different muscle groups may not be affected to the same extent by a prolonged critical illness. The relative contribution of diaphragmatic denervation in ICU patients with and without CRIMYNE has not been definitively determined. Prentice et $a{ }^{25}$ in a recent meta-analysis, maintain that there is evidence suggesting that respiratory muscles may be relatively spared from the damage that can occur as a result of immobility, prolonged-MV, and systemic inflammation in critical illness; however, the currently available bedside methods of measuring respiratory and peripheral muscle function in critically ill patients are somewhat inadequate.

We performed a prospective clinical study by enrolling septic patients with prolonged weaning who required MV for $\geq 14$ days. Our objective was to assess the presence of diaphragmatic dysfunction in patients with clinical signs of peripheral muscles CRYMINE.

\section{Methods}

This prospective cohort study was performed during a 6 months period in 2 ICUs (one mixed ICU and another cancer ICU) of the Complexo Hospitalar da Santa Casa, Porto Alegre, Brazil. The ethical committee of Complexo Hospitalar da Santa Casa approved this study beforehand, and written consent obtained from the subject, whenever possible, or from their next of kin.

\section{Inclusion and Exclusion Criteria}

Septic patients over 18 years of age, dependent on $\mathrm{MV} \geq 14$ days, and requiring prolonged weaning from 


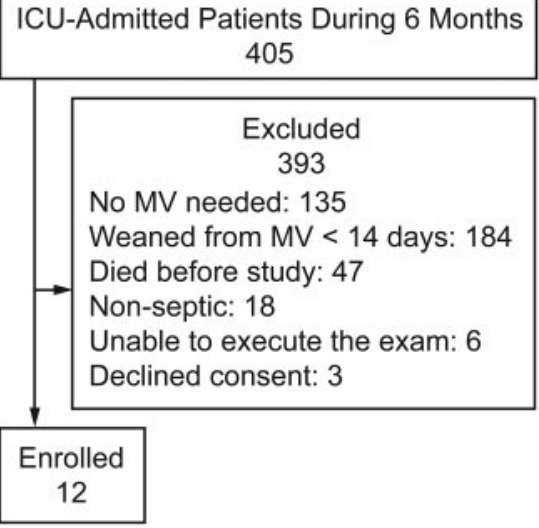

Figure. Trial profile. $\mathrm{MV}=$ mechanical ventilation

MV (subjects who failed at least 3 weaning attempts or required $7 \mathrm{~d}$ of weaning after the first SBT) were included consecutively. Subjects had to be awake or at a sedation level that would allow the subject to respond appropriately to verbal commands (Richmond Agitation Sedation Scale scale $\geq-2$ ).

Exclusion criteria were: CRIMYNE diagnosed within 24 hours of ICU admission; previous neuromuscular disorders; morbid obesity (body mass index of $>40 \mathrm{~kg} / \mathrm{m}^{2}$ ); lower limb disorders precluding nerve conduction study and EMG (eg, fractures, amputation, and plaster casts); brain death; Richmond Agitation Sedation Scale $<-1$; technical inability to conduct the diaphragmatic electrophysiological test; and refusal to participate. The excluded patients are shown in the Figure.

\section{Electrophysiological Investigations}

The complete electrophysiological tests performed on the subjects consisted of conventional motor (median and common peroneal nerves) and sensory nerve (median and sural nerves) conduction studies. Sensory nerve action potentials (SNAPs) were recorded from the median and sural nerves. For the median nerve, the ring recording electrodes were placed around the proximal (-) and distal (+) interphalangeal joints of the third digit; the nerve was stimulated at the wrist, on the volar surface, $2-3 \mathrm{~cm}$ proximal to the distal crease. For the sural nerve, the surface recording electrodes were placed immediately posteroinferior to the lateral malleolus (-) and $2-3 \mathrm{~cm}$ distally along the lateral dorsum of the foot $(+)$; the nerve was stimulated along the posterior surface of the leg (calf), slightly lateral to the midline and approximately $10-12 \mathrm{~cm}$ from the active electrode (-). The compound muscle action potentials (CMAPs) were recorded from the median (abductor pollicis brevis muscle) and common peroneal (extensor digitorum brevis muscle) nerves. For the median nerve, surface recording electrodes were placed over the belly $(-)$ and tendon $(+)$ of the abductor pollicis brevis; the nerve was stimulated at the wrist on the volar surface, $2-3 \mathrm{~cm}$ proximal to the distal crease, and at the elbow over the brachial pulse with the cathode at the volar crease. For the common peroneal nerve, surface recording electrodes were placed over the belly and tendon of the extensor digitorum brevis; the nerve was stimulated over the dorsum of the foot, near the ankle, $7-8 \mathrm{~cm}$ from the recording electrodes, and below the head of the fibula (below the knee). Incremental electrical stimulation of the nerves was used until the best SNAP or CMAP amplitudes were obtained.

If the clinical history and physical examination suggested a median nerve entrapment at the wrist, or the median sensory nerve conduction study was abnormal, the median nerve was substituted by the ulnar nerve. EMG was recorded using a coaxial needle electrode in the tibialis anterior, quadriceps femori, abductor pollicis brevis, and deltoid muscles; additional muscles were studied in some subjects.

Before performing electrophysiological tests, heat packs were applied to the skin if its temperature dropped below $33^{\circ} \mathrm{C}$. Electrophysiological diagnosis of CRIMYNE was achieved if the CMAP or SNAP amplitude of at least 2 nerves of 2 limbs was reduced below 2 standard deviations of the lower limit of normality, with or without abnormal spontaneous muscle activity.

To differentiate between CIP and CIM we used electrophysiological criteria: nerve conduction (reduced SNAP amplitude in CIP, and normal SNAP amplitude in CIM); needle EMG (CIP: abnormal spontaneous activity common, large and polyphasic motor unit potentials, and reduced recruitment; CIM: mild or non-abnormal spontaneous activity, small polyphasic motor unit potentials, and early recruitment); and direct muscle stimulation (normal in CIP, and absent or reduced in CIM).

Diaphragmatic involvement was determined based on electrodiagnostic studies that included phrenic nerve conduction and needle EMG of the diaphragm. Phrenic nerve conduction studies were performed with percutaneous stimulation in the supraclavicular fossa, and recording from the ipsilateral diaphragm with muscle needle electrodes. Four measurements of the diaphragmatic CMAP were determined: the latency to the onset of the negative peak; the CMAP amplitude from the baseline to the negative peak; the negative peak area; and the CMAP duration from the negative peak onset to the return to baseline. Needle EMG of the diaphragm was performed with a monopolar needle electrode inserted between the anterior axillary and medial clavicular lines, just above the costal margin.

\section{Clinical Management and Data Collection}

Patient treatment, including correction of electrolytes (sodium, potassium, magnesium, and phosphorus) and con- 
Table 1. Characteristics of the Study Subjects

\begin{tabular}{|c|c|c|c|c|c|c|c|c|c|c|c|}
\hline \multirow[b]{2}{*}{$\begin{array}{l}\text { Number of } \\
\text { Subject }\end{array}$} & \multirow[b]{2}{*}{ Sex } & \multirow[b]{2}{*}{$\begin{array}{l}\text { Age, } \\
\text { (y) }\end{array}$} & \multirow[b]{2}{*}{$\begin{array}{l}\text { Reason } \\
\text { for MV }\end{array}$} & \multirow[b]{2}{*}{$\begin{array}{l}\text { Days on } \\
\text { MV }\end{array}$} & \multirow[b]{2}{*}{$\begin{array}{l}\text { ICU } \\
\text { Stay } \\
\text { (d) }\end{array}$} & \multirow[b]{2}{*}{$\begin{array}{l}\text { APACHE II } \\
\text { Score }\end{array}$} & \multirow[b]{2}{*}{ Previous Diseases } & \multicolumn{3}{|c|}{ At Weaning Time } & \multirow[b]{2}{*}{ Outcome } \\
\hline & & & & & & & & $\begin{array}{l}\text { SOFA } \\
\text { Score }\end{array}$ & $\begin{array}{l}\text { Using } \\
\text { Pressors } \\
\text { (NE) }\end{array}$ & Dialysis & \\
\hline 1 & Female & 76 & ALI & 36 & 36 & 22 & $\begin{array}{l}\text { Diabetes mellitus, } \\
\text { cancer }\end{array}$ & 7 & Yes & Yes & Died \\
\hline 2 & Female & 66 & ALI & 35 & 35 & 24 & Asthma & 6 & Yes & Yes & Died \\
\hline 3 & Female & 83 & ALI & 17 & 17 & 25 & No & 5 & No & Yes & Died \\
\hline 4 & Male & 41 & ALI & 15 & 20 & 11 & No & 7 & No & No & Survived \\
\hline 5 & Female & 72 & ALI & 36 & 42 & 31 & COPD & 7 & No & No & Died \\
\hline 6 & Female & 93 & Postoperative & 49 & 49 & 36 & Cancer & 7 & No & Yes & Died \\
\hline 7 & Female & 64 & Stroke & 17 & 29 & 19 & $\begin{array}{l}\text { Diabetes mellitus, } \\
\text { COPD }\end{array}$ & 7 & Yes & No & Survived \\
\hline 8 & Male & 73 & ALI & 30 & 30 & 20 & $\begin{array}{l}\text { Diabetes mellitus, } \\
\text { COPD }\end{array}$ & 7 & Yes & Yes & Died \\
\hline 9 & Male & 47 & ALI & 23 & 28 & 18 & No & 5 & No & No & Survived \\
\hline 10 & Male & 66 & ALI & 15 & 28 & 22 & $\begin{array}{l}\text { Alcoholism, COPD, } \\
\text { cancer }\end{array}$ & 4 & Yes & Yes & Survived \\
\hline 11 & Female & 76 & Stroke & 34 & 34 & 27 & COPD & 7 & No & Yes & Died \\
\hline 12 & Male & 70 & ALI & 22 & 30 & 17 & Alcoholism, cancer & 6 & No & No & Survived \\
\hline \multicolumn{12}{|c|}{$\begin{array}{l}\text { MV = mechanical ventilation } \\
\text { APACHE = Acute Physiology and Chronic Health Evaluation } \\
\text { SOFA = Sequential Organ Failure Assessment } \\
\mathrm{NE}=\text { norepinephrine } \\
\mathrm{ALI}=\text { acute lung injury }\end{array}$} \\
\hline
\end{tabular}

trol of blood glucose, conformed to accepted standards. Intravenous insulin, preferably using a pump, was started if blood glucose level exceeded $200 \mathrm{mg} / \mathrm{dL}$, with a target of $<160 \mathrm{mg} / \mathrm{dL} .{ }^{26}$ ICU staff members were in charge of hemodynamic, ventilatory, and dialysis management.

Intensivists and clinical neurophysiologists were unaware of each other's diagnoses. All of the electrophysiological recordings performed by a neurophysiologist (PS) were re-examined by one expert physician (FTR) for quality assessment.

The data collected were: age, sex, previous diseases, reason for MV need, days on MV, ICU stay, Acute Physiology and Chronic Health Evaluation II, and ICU outcome (lived or died). The plasma creatine phosphokinase, use of vasopressor (norepinephrine), need for dialysis, and Sequential Organ Failure Assessment score during the weaning process were also collected.

Peripheral muscle power was tested by a neurologist (PS) and conventionally assessed using the Medical Research Council (MRC) scale: $5=$ normal power, $4=$ moderate movement of limbs against resistance, $3=$ movement of limbs against gravity but not resistance, $2=$ movement of limbs with gravity removed, $1=$ flicker, and $0=$ no movement. For research purposes, the muscle power was graded as $\mathrm{MG}+$ (moves limbs against gravity, including grades 3,4 , and 5 of MRC) or
MG- (no movement against gravity, including grades 0 , 1 , and 3 of MRC).

\section{Data Presentation and Statistical Analysis}

Continuous variables were expressed as medians (minimum-maximum) and discrete variables as counts (percentage) unless otherwise stated. Differences in the study population were analyzed by means of the Student $t$ test, Mann-Whitney $U$ test, or chi-square test (or Fisher exact test), as appropriate. All tests were 2-tailed, and a $P$ value of $<.05$ was used to define a statistically significant difference. The statistical analysis was conducted with commercially available software (SPSS 16.0, SPSS, Chicago, Illinois).

\section{Results}

Twelve subjects were enrolled during 6 months of study. Subject characteristics are shown in Table 1. Four subjects were male, the median age was 71 (41-93) years, and the median APACHE II score was 22 (11-36). The median time on MV was 26.5 (11-36) days, and during this period the median use of opioid was 6.5 (3-36) days, that of benzodiazepine 13 (1-30) days, and the use of corticosteroids 9 (1-35) days. All subjects received corticosteroids, 
Table 2. Electrophysiological and Neurological Findings

\begin{tabular}{|c|c|c|c|}
\hline \multirow[b]{2}{*}{$\begin{array}{c}\text { Number of } \\
\text { Subject }\end{array}$} & \multicolumn{2}{|c|}{ Electrophysiological Findings } & \multirow[b]{2}{*}{$\begin{array}{l}\text { Clinical Finding: } \\
\text { Moves Limbs Agains } \\
\text { Gravity (MG+) }\end{array}$} \\
\hline & $\begin{array}{l}\text { Peripheral } \\
\text { Muscles }\end{array}$ & $\begin{array}{l}\text { Diaphragm } \\
\text { Injury }\end{array}$ & \\
\hline 1 & CIM & Yes & No \\
\hline 2 & $\mathrm{CIP}+\mathrm{CIM}$ & Yes & No \\
\hline 3 & CIP & No & No \\
\hline 4 & CIM & Yes & Yes \\
\hline 5 & CIM & Yes & No \\
\hline 6 & CIP & Yes & Yes \\
\hline 7 & Normal & No & No \\
\hline 8 & CIP & Yes & No \\
\hline 9 & Normal & No & Yes \\
\hline 10 & Normal & No & Yes \\
\hline 11 & CIM & Yes & No \\
\hline 12 & $\mathrm{CIP}+\mathrm{CIM}$ & Yes & No \\
\hline
\end{tabular}

opioids, and benzodiazepines. Only 2 subjects received neuromuscular blockage (subject 8 for $1 \mathrm{~d}$, and subject 9 for $10 \mathrm{~d}$ ). No subject was treated with aminoglycosides. During the weaning process, all subjects underwent tracheotomy, except 2 subjects (subjects 7 and 9). Two subjects had elevated creatine phosphokinase levels (subjects 4 and 5).

Electrophysiological signs of peripheral CRIMYNE occurred in 9 subjects (Table 2), 7 of whom died in the ICU. Three subjects developed CIP, 4 CIM, and 2 both. Only one subject who developed peripheral CRIMYNE (subject 3) did not develop diaphragmatic CRIMYNE (see Table 2). No subject developed diaphragm involvement alone, without peripheral CRIMYNE. Thus, electrophysiological signs of diaphragmatic CRIMYNE occurred in 8 of the 9 subjects with peripheral CRIMYNE.

As regards peripheral muscle power, 8/12 subjects were $\mathrm{MG}-$, and this finding was related to the presence of peripheral CRIMYNE (7 of 9 subjects) and diaphragmatic CRIMYNE (6 of 8 subjects). The mortality rate was higher in subjects with CRIMYNE $(77.8 \%$ vs $0 \%$, $P<.001)$.

\section{Discussion}

Our findings suggest that CRIMYNE is common in septic subjects with prolonged weaning from $M V(M V \geq 14 d)$. CRIMYNE, as assessed by peripheral positive electrophysiological tests, was associated with a higher incidence of diaphragmatic impairment and an inability to move limbs against gravity, based on clinical strength testing.

The occurrence of ICU-acquired weakness varies substantially, depending on the diagnostic method used, ${ }^{27,28}$ the timing of examination, ${ }^{4,6}$ and the type of population under study. ${ }^{29}$ Several studies ${ }^{18,21,22,30}$ have suggested that the incidence of weakness (clinical evidence or abnormalities on nerve-conduction studies and/or EMG) in MV patients $\geq 4-7$ days is very high (33-82\%). However, these studies included patients with altered levels of consciousness, so they relied on nerve-conduction studies and EMG testing or non-rigorous definitions of weakness for diagnosis, which may have resulted in overestimation of weakness, and for this reason are subject to criticism.

Methodologically speaking, the most rigorous studies were conducted by De Jonghe et $\mathrm{al}^{11}$ and Latronico et al. ${ }^{4}$ The former prospectively identified subjects who were on MV $\geq 7$ days, and evaluated them for weakness only when they awakened and were able to cooperate with physical examination. The authors showed that $25 \%$ of the surviving subjects developed severe weakness. Latronico et $\mathrm{al},{ }^{4}$ in their prospective and multicenter study (92 participant ICUs) conducted electrophysiological studies on a daily basis on subjects admitted to ICU, and showed electrophysiological signs of CRIMYNE in 30.4\% (95\% CI $21.9-40.4 \%$ ) of these subjects. Median time from ICU admission to CRIMYNE was 6 days (95\% CI 5-9 d).

Difficult weaning from the ventilator constitutes a major challenge for intensivists. Some authors estimate that the presence of CRIMYNE could prolong dependence on MV, ${ }^{18,20,21}$ while others disagree. ${ }^{22,23}$ Maher et $\mathrm{al}^{31}$ evaluated the presence of neuromuscular disorders (CIP, CIM, Guillain-Barré syndrome, diabetic neuropathy, uremic neuropathy, abnormality of central drive, unilateral phrenic nerve palsy, and neuromuscular transmission defect) and demonstrated that patients with more severe polyneuropathy took longer to wean: a mean of $136 \mathrm{~d}$ versus $52 \mathrm{~d}$ $(P=.007)$. The elegant study of Garnacho-Montero et $\mathrm{al}^{21}$ on 64 critically ill septic patients, showed that the duration of the weaning period was significantly higher in patients with CRIMYNE (median $15 \mathrm{~d}$ vs $2 \mathrm{~d}, P<.001$ ). Multiple logistic regression analysis indicated that CIP was the only risk factor independently associated with weaning failure (odds ratio 15.4, 95\% CI 4.55-52.3, $P<.001$ ). Our data indicate that 9 subjects with prolonged weaning from MV (those who require $>3$ SBTs or $\geq 7 \mathrm{~d}$ of weaning after the first SBT) show electrophysiological findings of peripheral CRIMYNE, and this finding is probably related to the failure to wean from MV.

In preventing CRIMYNE from developing, it is likely that the avoidance of potentially triggering or priming factors, such as aminoglycosides, corticosteroids, and neuromuscular blockage agents, will reduce the incidence of ICU-acquired neuromuscular abnormalities.6,14,32 The prompt treatment of sepsis is also essential.6,20 Physical therapy and rehabilitation may be helpful in accelerating recovery. ${ }^{33}$ Furthermore, a recent Cochrane meta-analysis, ${ }^{14}$ based on 2,748 randomized patients, concluded that 


\section{The Critical Illness Polyneuropathy in Septic Patients With Prolonged Weaning}

the incidence of CRIMYNE was significantly reduced in patients who received intensive insulin therapy during their ICU stay (relative risk $0.60,95 \%$ CI $0.49-0.74$ ). The duration of MV, duration of ICU stay, and 180-day mortality were also significantly reduced with intensive insulin therapy. All septic subjects of our sample were submitted to glycemic control, based in insulin therapy infusion proto$\mathrm{col}$, and received early motor physiotherapy during ICU stay, in order to avoid confounding bias.

The respiratory muscles carry the entire burden of the increase in respiratory work that occurs during the weaning failure process. The imbalance between energy supply and demand of the respiratory muscles suggests that inspiratory muscle fatigue is frequently a final common pathway leading to an inability to sustain spontaneous breathing and thus to weaning failure. ${ }^{34}$ The overall strength of the inspiratory muscles is usually clinically assessed by measuring maximal inspiratory pressure. De Jonghe et al, ${ }^{35}$ after analyzing 116 patients who were MV-dependent for $\geq 7$ days, showed that respiratory and limb muscle strength were both altered after one week of MV. In that study, respiratory muscle weakness (low maximal inspiratory pressure [hazard ratio $1.86,95 \%$ CI $1.07-3.23]$ ), and peripheral muscle weakness (low MRC score [hazard ratio $1.96,95 \%$ CI 1.27-3.02]) were associated with prolonged ventilation. Our subjects were MV-dependent, and the study was not designed to compare success and failure of weaning from MV in the acute setting, but the incidence of peripheral and diaphragmatic CRIMYNE in patients with prolonged weaning; and CRIMYNE was assessed by means of electrophysiological muscle studies, and not by pressure measurements (maximal inspiratory pressure).

A striking feature of those patients who fail to wean from MV is the timing at which different muscle groups become active. Parthasarathy et $\mathrm{al}^{36}$ showed that this sequence begins with activity of the diaphragm and with greater activity of inspiratory rib-cage muscles than is the case in the success patients; recruitment of sternomastoids and rib-cage muscles is near maximum within 4 min after trial commencement, while the expiratory muscles are not recruited until 17-20 min. The fundamental role of the diaphragm on ventilatory mechanics and the earliness of its injury during weaning failure make it a key muscle for studies on respiratory failure, and define the importance of studying it separately from the others respiratory muscle groups. However, Latronico et $\mathrm{al}^{8}$ suggest that CRIMYNE is a key determinant of prolonged MV and of failed weaning from the ventilator; nevertheless, a direct relationship with acute neuromuscular abnormalities of the respiratory system (phrenic neuropathy, diaphragm myopathy) is still lacking.

Although life-saving, MV is associated with numerous complications. These include pneumonia, cardiovascular compromise, barotrauma, and ventilator-induced lung injury (in humans, dysfunction of the diaphragm and decrease in its force-generating capacity: a condition referred to as ventilator-induced diaphragmatic dysfunction). ${ }^{37}$ The decrease in diaphragmatic contractility is time-dependent and worsens as MV is prolonged. Atrophy, fiber remodeling, oxidative stress, and structural injury have been implicated as potential mechanisms of ventilator-induced diaphragmatic dysfunction. ${ }^{37-39}$ Hermans et al, ${ }^{14}$ using a new technique of transdiaphragmatic pressure after magnetic stimulation that allows physicians to evaluate diaphragm strength, showed that duration of MV is associated with a logarithmic decline in diaphragmatic force, which is compatible with the concept of ventilator-induced diaphragmatic dysfunction. Our sample included patients who were MV-dependent for $\geq 14$ days, and data suggest that, based on this mechanism, prolonged MV may have contributed to the high incidence of diaphragmatic CRIMYNE in this population.

Prospective studies on patients who have been ventilated for over 7 days have reported increased hospital mortality associated with CRIMYNE. ${ }^{19,22}$ In fact, the development of CIP or CIM early in the course of critical illness may predict mortality. Khan et al ${ }^{40}$ carried out studies on 48 patients with severe sepsis, and found that abnormal nerve conduction studies obtained within 72 hours from ICU admission predicted hospital mortality ( $55 \%$ vs $0 \%$, $P<.001)$. In agreement, our mortality rate was higher in patients with CRIMYNE $(77.8 \%$ vs $0 \%, P<.001)$. The outcome of these patients is associated with prolonged duration of MV and increased hospital-stay and ICU-stay. ${ }^{18,21,22}$ Thus, the presence of acquired paresis can influence the clinical decision to pursue early tracheotomy and arrange for long-term care after hospital discharge. Tracheotomy was performed in 10 of our subjects.

The pathophysiologic mechanisms leading to weaning failure in this group may be complex and dependent on many factors, with several potentially reversible etiologies for weaning failure, including respiratory and/or cardiac load, neuromuscular competence (central and peripheral), critical illness neuromuscular abnormalities, neuropsychological factors, and metabolic and endocrine disorders. In this group of chronically critically ill patients, the need emerges for a comprehensive approach to ongoing surveillance for any reversible or irreversible factors. Since many patients with long-term MV have poor nutritional status and end-stage respiratory diseases, nutrition and dietary intake-related problems need to be carefully assessed and corrected. We evaluated diaphragmatic CRIMYNE, which is not commonly studied.

The limitations of our study are as follows. First, we report a small sample of subjects $(n=12)$ and subjects with previous conditions that can lead to neuromyopathy. 


\section{The Critical Illness Polyneuropathy in Septic Patients With Prolonged Weaning}

Second, we provide no data on muscle biopsy to allow differential diagnosis of myopathy and show severity of myopathic changes. ${ }^{25}$ Finally, we performed no assessment of muscle contraction sequence to compare spontaneous with supported ventilation.

\section{Conclusions}

Our pilot findings suggest that CRIMYNE, as assessed by peripheral positive electrophysiological tests, is associated with a higher incidence of diaphragmatic impairment and an inability to move limbs against gravity, based on clinical strength testing.

\section{ACKNOWLEDGMENTS}

The authors would like to thank the Universidade Federal de Ciências da Saúde de Porto Alegre and Complexo Hospitalar da Santa Casa, Porto Alegre, Brazil. A special thanks to Dr André Peretti Torelly and Jorge Amilton Höher, Complexo Hospitalar da Santa Casa, who allowed and encouraged this study.

\section{REFERENCES}

1. Desai SV, Law TJ, Needham DM. Long-term complications of critical care. Crit Care Med 2011;39(2):371-379.

2. Nelson JE, Cox CE, Hope AA, Carson SS. Chronic critical illness. Am J Respir Crit Care Med 2010;182(4):446-454.

3. Oeyen SG, Vandijck DM, Benoit DD, Annemans L, Decruyenaere JM. Quality of life after intensive care: a systematic review of the literature. Crit Care Med 2010;38(12):2386-2400.

4. Latronico N, Bertolini G, Guarneri B, Botteri M, Peli E, Andreoletti $\mathrm{S}$, et al. Simplified electrophysiological evaluation of peripheral nerves in critically ill patients: the Italian multi-centre CRIMYNE study. Crit Care 2007;11(1):R11-R21.

5. Vles W, Steyerberg E, Essink-Bot M, Beeck Ev, Meeuwis J, Leenen L. Prevalence and determinants of disabilities and return to work after major trauma. J Trauma 2005;58(1):126-135.

6. Deem S. Intensive-care-unit-acquired muscle weakness. Respir Care 2006;51(9):1042-1052.

7. Sharshar T, Bastuji-Garin S, Stevens R, Durand MC, Malissin I, Rodriguez P, et al. Presence and severity of intensive care unitacquired paresis at time of awakening are associated with increased intensive care unit and hospital mortality. Crit Care Med 2009;37(12): 3047-3053.

8. Latronico N, Guarneri B. Critical illness myopathy and neuropathy. Minerva Anestesiol 2008;74(6):319-327.

9. Latronico N, Peli E, Botteri M. Critical illness myopathy and neuropathy. Curr Opin Crit Care 2005;11(2):126-132.

10. Latronico N, Fenzi F, Recupero D, Guarneri B, Tomelleri G, Tonin $\mathrm{P}$, et al. Critical illness myopathy and neuropathy. Lancet 1996; 347(9015):1579-1582.

11. De Jonghe B, Sharshar T, Lefaucher J, Althier FJ, Durand-Zaleski I, Bolssarsar M, et al. Paresis acquired in intensive care unit: a prospective multicentric study. JAMA 2002;288(22):1639-1641.
12. Brunello A, Haenggi M, Wigger O, Porta F, Takala J, Jakob S. Usefulness of a clinical diagnosis of ICU-acquired paresis to predict outcome in patients with SIRS and acute respiratory failure. Intensive Care Med 2010;36(1):66-74.

13. Schweickert WD, Hall J. ICU-acquired weakness. Chest 2007;131(5): 1541-1549.

14. Hermans G, De Jonghe B, Bruyninckx F, Van-den-Berghe G. Interventions for preventing critical illness polyneuropathy and critical illness myopathy. Cochrane Database Syst Rev 2009;(1):CD006832. DOI: 10.1002/14651858.CD006832.pub2.

15. Boles J, Bion J, Connors A, Herridge M, Marsh B, Melot C, et al. Weaning from mechanical ventilation. Eur Respir J 2007;29(5): 10331056.

16. Brochard L, Rauss A, Benito S, Conte G, Mancebo J, Rekik N, et al. Comparison of three methods of gradual withdrawal from ventilatory support during weaning from mechanical ventilation. Am J Respir Crit Care 1994;150(4):896-903.

17. Esteban A, Alía I, Tobin M, Gil A, Gordo F, Vallverdú I, et al. Effect of spontaneous breathing trial duration on outcome of attempts to discontinue mechanical ventilation. Spanish Lung Failure Collaborative Group. Am J Respir Crit Care 1999;159(2):512-518.

18. Leijten F, de-Weerd JH, Poortvliet D, de-Weerd A. The role of polyneuropathy in motoconvalescence after prolonged mechanical ventilation. JAMA 1995;274(15):1221-1225.

19. Garnacho-Montero J, Madrazo-Osura J, Garcia-Garmendia J, OrtizLeyba C, Jiménez-Jiménez FJ, Barrero-Almodóvar A, et al. Critical illness polyneuropathy: risk factors and clinical consequences. A cohort study in septic patients. Intensive Care Med 2001;27(8):12881296.

20. Thiele R, Jakob H, Hund E, Tamtzky S, Keller S, Kamler M, et al. Sepsis and catecholamine support are the major risk factors for critical illness polyneuropathy after open heart surgery. Thorac Cardiovasc Surg 2000;48(3):145-150.

21. Garnacho-Montero J, Amaya-Villar R, Garcia-Garmendia J, Madrazo-Osuna J, Ortiz-Leyba C. Effect of critical illness polyneuropathy on the withdrawal of mechanical ventilation and length of stay in septic patients. Crit Care Med 2005;33(2):349-354.

22. Leijten F, de-Weerd A, Poortvliet D, de-Ridder V, Ulrich C, deWeerd JH. Critical illness polyneuropathy in multiple organ dysfunction syndrome and weaning from the ventilator. Intensive Care Med 1996;22(9):856-861.

23. Sander H, Saadeh P, Chandswang N, Greenbaum D, Chokroverty S. Diaphragmatic denervation in intensive care unit patients. Electromyogr Clin Neurophysiol 1999;39(1):3-5.

24. Khan J, Harrison TB, Rich MM. Mechanisms of neuromuscular dysfunction in critical illness. Crit Care Clin 2008;24(1):165-175.

25. Prentice C, Paratz J, Bersten A. Differences in the degree of respiratory and peripheral muscle impairment are evident on clinical, electrophysiological and biopsy testing in critically ill adults: a qualitative systematic review. Crit Care Resusc 2010;12(2):111-120.

26. Egi M, Finfer S, Bellomo R. Glycemic control in the ICU. Chest 2011;140(1):212-220.

27. Dhand UK. Clinical approach to the weak patient in the intensive care unit. Respir Care 2006;51(9):1024-1041.

28. Lefaucheur J, Nordine T, Rodriguez P, Brochard L. Origin of ICU acquired paresis determined by direct muscle stimulation. J Neurol Neurosurg Psychiatry 2006;77(4):500-506.

29. Graggen W, Lin C, Howard R, Beale R, Bostock H. Nerve excitability changes in critical illness polyneuropathy. Brain 2006;129(Pt 9):2461-2470.

30. de-Letter M, Schmitz P, Visser L, Verheur FA, Schellens RL, Opde-Coul DA, van-der-Meché FG. Risk factors for the development of 


\section{The Critical Illness Polyneuropathy in Septic Patients With Prolonged Weaning}

polyneuropathy and myopathy in critically ill patients. Crit Care Med 2001;29(12):2281-2286.

31. Maher J, Rutledge F, Remtulla H, Parkes A, Bernardi L, Bolton C. Neuromuscular disorders associated with failure to wean from the ventilator. Intensive Care Med 1995;21(9):737-743.

32. Latronico N, Rasulo F. Presentation and management of ICU myopathy and neuropathy. Curr Opin Crit Care 2010;16(2):123-127.

33. Needham DM. Mobilizing patients in the intensive care unit: improving neuromuscular weakness and physical function. JAMA 2008; 300(14):1685-1690

34. Tobin MJ, Laghi F, Brochard L. Role of the respiratory muscles in acute respiratory failure of COPD: lessons from weaning failure. J Appl Physiol 2009;107(3):962-970.

35. De Jonghe BD, Bastuji-Garin S, Durand M, Malissin I, Rodrigues P, Cerf C, et al. Respiratory weakness is associated with limb weakness and delayed weaning in critical illness. Crit Care Med 2007;35(9): 2007-2015.

36. Parthasarathy S, Jubran A, Laghi F, Tobin MJ. Sternomastoid, rib cage, and expiratory muscle activity during weaning failure. J Appl Physiol 2007;103(1):140-147

37. Jubran A. Critical illness and mechanical ventilation: effects on the diaphragm. Respir Care 2006;51(9):1054-1061.

38. Powers SK, Kavazis AN, Levine S. Prolonged mechanical ventilation alters diaphragmatic structure and function. Crit Care Med 2009; 37(Suppl 10):S347-S353.

39. Petrof BJ, Jaberb S, Mateckic S. Ventilator-induced diaphragmatic dysfunction. Curr Opin Crit Care 2010;16(1):19-25.

40. Khan J, Harrison T, Rich M, Moss M. Early development of critical illness myopathy and neuropathy in patients with severe sepsis. Neurology 2006;24(8):1421-1425. 